\title{
Design and Test Results of a 600-kW Tetrode Amplifier for the Superconducting Super Collider*
}

\author{
Daniel E. Rees and Donna L. Brittain \\ Los Alamos National Laboratory \\ P.O. Box 1663, Los Alamos, NM 87545 \\ James M. Grippe and Orlando Marrufo \\ Superconducting Super Collider Laboratory \\ 2550 Beckleymeade Ave., Dallas, TX 75237
}

\begin{abstract}
This paper describes the design and testing of a pulsed $600-\mathrm{kW}$ tetrode amplifier that will be used to drive a radiofrequency quadrupo!e (RFQ) for the Superconducting Super Collider (SSC). Three stages of amplification provide a nominal gain of $77 \mathrm{~dB}$ and peak output power of $600 \mathrm{~kW}$. The amplifier is operated at a pulse width of $100 \mu \mathrm{s}$ and a repetition frequency of $10 \mathrm{~Hz}$. This paper presents the RF design and calculated operating conditions for the amplifier. Details of the electrical design are presenied, along with test results.
\end{abstract}

\section{INTRODUCTION}

The purpose of the radio-frequency quadrupole (RFQ) amplifier is to provide an adequate amount of power at the proper operating frequency to enable the RFQ to increase the veloxity of the input beam from .00864 times the speed of light to .0729 times the speed of light. The energy in the beam increases from $35 \mathrm{keV}$ to $2.5 \mathrm{MeV}$. To perform this function the amplifier must provide a minimum of $225 \mathrm{~kW}$ at a frequency of $427.617 \mathrm{MHz}$ at each of two input ports of the RFQ. In addition, enough overdrive must be available to cnsure a fast fill time. To adequately meet the requirements, the amplifier must meet the performance requirements specified in Table $i$.

Table 1

6(0)-kW Amplifier Electrical Requirements

\begin{tabular}{|c|c|}
\hline Operating Frequency & $427.617 \mathrm{MHz}$ \\
\hline Handuidth & $3(x) \mathrm{kHz}$ (minimum) \\
\hline Power Output & $(x(x) \times W($ neak $)$ \\
\hline Gain & $77 \mathrm{~dB}$ (nomina) \\
\hline Puise Length & $1(x) \mu s$ \\
\hline Pulse Repetition Rate & $1010 \mathrm{~Hz}$ \\
\hline Pulce I. vp & $1 \%$ (maximum) \\
\hline Input VSWR & $1.5: 1$ (maximum) \\
\hline l.incar Range & $\begin{array}{c}15 \% \text { w } 8.5 \% \text { of peak } \\
\text { power mating }\end{array}$ \\
\hline Amplitude Stubility & $\begin{array}{c}0.5 \text { dB within any one } \\
\text { hour }\end{array}$ \\
\hline
\end{tabular}

* This work supported by the U.S. I kyatument of Eimergy.

\begin{tabular}{|l|c|}
\hline Phase Stability & $\begin{array}{c}<10 \mathrm{deg} \text {. within any one } \\
\text { hour }\end{array}$ \\
\hline Spurious Signals & $260 \mathrm{~dB}$ below carrier \\
\hline Prime Power & 208 VAC, 3 phase \\
\hline
\end{tabular}

A similar amplifier with slighly different performance characteristics-300-kW, 425-MHz, 2\% duty factor-was developed for the Ground Test Accelerator (GTA). This GTA amplifier was modified to meet the Superconducting Super Collider (SSC) requirements.

The SSC amplifier is located in the source area of the LINAC Building. Cooling water, whose temperature cannot exceed $95^{\circ} \mathrm{C}$, is provided for cooling the output cavity. Building temperature is well regulated. Therefore, no special provicions are necessary for air cooling, other than fans and? blowers.

input RF is obtained from the low-level RF control systern, which is designed to maintain cavity ficld anplitude and phase to a preset level in the presence of beam-induced field perturbations. A high-power cinculator isolates the load from the amplifier. The load on the amplifier can be manually switched between the accelerating cavity or a test Icard via a coaxial switch.

\section{OPERATING CONDITIONS AND AMPLIFIER CONFIGURATION}

The SSC amplifier is a three-amplifier chain, consisting of an $800-W$ solid-state driver, an intermediate triode amplifier, and a final tetrode amplifier.

The solid-state amplifier requires a maximum input of $13 \mathrm{dBm}$ and can paovide up $t o \mathrm{~g}(\mathrm{X}) \mathrm{W}$ of power for $2-\mathrm{ms}$ pulses at a maximum repetition rate of $10 \mathrm{~Hz}$. The amplifier has a $4 \%$ bandwidh, and its output is protected by an internal circulator. It is comtigured to accept an optical trigger, which is usecl in conjunction with as PIN! dicke: swilch (1) act as an RF' gate.

The intermediak: amplifier uses an LIMAC 8938 iriexle. It is conligured to te cathoxle-moxlulated with a prounded grit. A high-power hexfet is driven into salluration (4) modulate the cathode: The triode is operated at its ratcol do voltage of $4 \mathrm{kV}$ by means of a $5 \mathrm{KV}$ power supply that charges a small capa:itor bank to provide the pulsed comrent. 
Approximately $50 \mathrm{ohms}$ of series resistance is inserted between the capacitor and triode to dissipate the energy in case of an internal tube arc.

The final amplifier is a Burle 4616 tetrode. It requires approximately $500 \mathrm{~W}$ of filament power. The operating conditions for the cathode, as well as pertinent maximum operating conditions, are shown in Table 2 . The final amplifier requires three high-voltage power supplies. The $25-\mathrm{kV}$ plate voltage is supplied by a $30-\mathrm{kV}$ supply with an average current capability of $80 \mathrm{~mA}$. This supply has a crowbar and small capacitor bank sized to meet the $1 \%$ pulse droop requirement. A $3-k V$ screen supply and $1-k V$ grid supply are also requircd. The screen supply feeds a small capacitor bank to supply the pulied screen current. The screen supply does not use a srowbar triggered simultaneously with the plaic supply crowbar, Rather, series resistance is used to limit the current and dissipate the energy that could result from a tube arc.

To provide the required lincar range of operation, the solid-state amplifier is operated class $A B$, the intermediate triode amplifier is operated class $A$, and the final tetrode amplifier is operate class $\mathbf{B}$. The intermediate triode amplifier takes advantage of the cathode modulator to operate class A during the RF pulse without suffering the corresponding anode dissipation during the incerval when the RF pulse is not present.

Table 2

4616 Operating Conditions

\begin{tabular}{|c|c|c|}
\hline Operating Parameter & Value & $\begin{array}{c}\text { Max. } \\
\text { Value at } \\
100 \mu s\end{array}$ \\
\hline 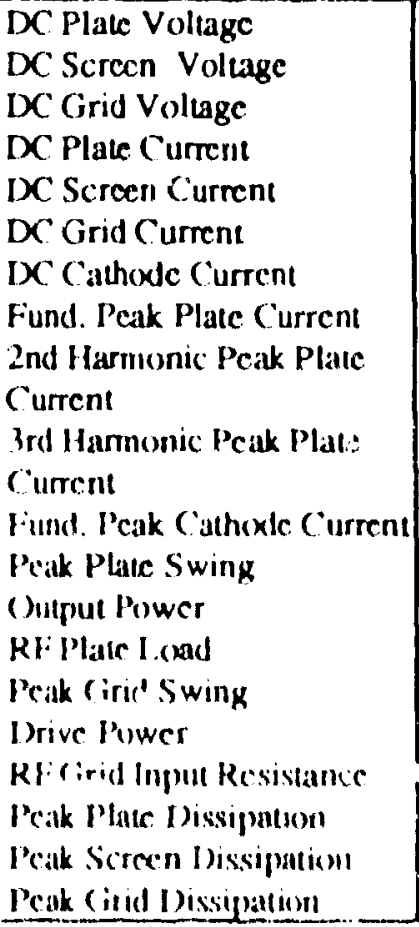 & 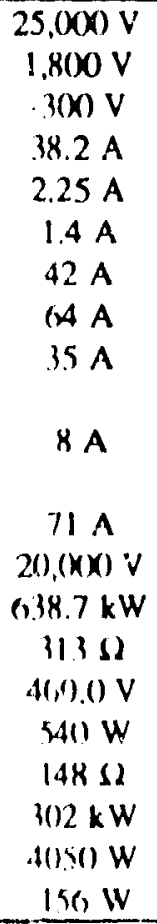 & $\begin{array}{l}80 \mathrm{~A} \\
15 \mathrm{~A} \\
15 \mathrm{~A}\end{array}$ \\
\hline
\end{tabular}

\section{TEST RESULTS}

Test results for the $600-\mathrm{kW}$ amplifier are shown in Figures 1 and 2. Figure 1 shows the frequency response of the amplifier at the upper end of the linear range. Figure 2 shows the linear performance of the amplifier. The test conditions are summarized in Table 3. Table 4 summarizes the test results.

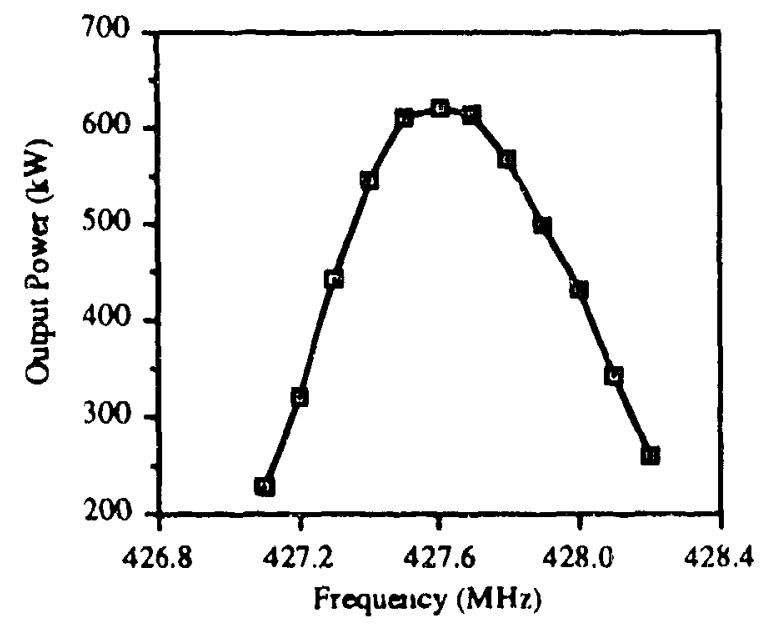

Figure 1. Frequency Response

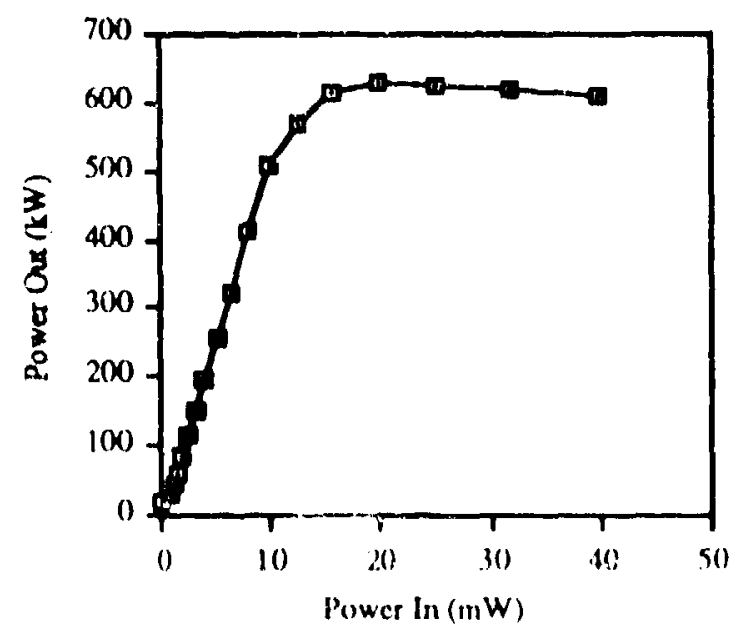

Figue 2. I.inear Dynamic Range

Tuble 3

Test Cherating Conditions

\begin{tabular}{|l|c|}
\hline Paranneter & Value \\
\hline 1616 (irid Voltage & $-380 \mathrm{~V}$ \\
4616 Anoxle Voltage & $26 .(x)(x) \mathrm{V}$ \\
4616 Sereen Voltuge & $2(x) \mathrm{V}$ \\
4616 Filument Current & $510 \mathrm{~A}$ \\
\hline
\end{tabular}


Table 4

Test Results

\begin{tabular}{|l|c|}
\hline Parameter & Value \\
\hline Maximum Power Outpul & $625 \mathrm{~kW}$ \\
Linear Range & $200 \mathrm{~kW}$ to $500 \mathrm{~kW}$ \\
Gain & $77.4 \mathrm{~dB}$ (nominal) \\
3-dB Bandwidth & $900 \mathrm{kHz}$ \\
1-dB Bandwidth & $550 \mathrm{kHz}$ \\
Efficiency & $63 \%$ \\
\hline
\end{tabular}

Note: The dc anode voltage used for testing is slightly above the ratings. This was necessary because the high. voltage dc power supply had a series resistance that would drop approximately $1 \mathrm{kV}$ during the RF pulse. We did not suffer any degradation in operational testing as a result of the 26-kV anode voltage, however.

\section{CONCLUSION}

We have successfully modified the GTA $300-\mathrm{kW}$ amplifier to operate as a $600-\mathrm{kW}$ amplifier for SSC. The amplifier met or exceeded all performance requirements and is currently in service at SSC. 